\title{
A Modelica-based environment for the simulation of hybrid-electric propulsion systems
}

\author{
Max J. Arzberger Dirk Zimmer \\ Insitute of System Dynamics and Control, \\ DLR German Aerospace Center, Germany, \\ \{max.arzberger, dirk.zimmer\}@dlr.com
}

\begin{abstract}
In this paper, a framework for the modeling of hybrid electric propulsion system architectures for aviation is presented in form of a novel Modelica library. The scope and requirements for an aviation power train modelling framework are specified. The presentation then follows the hierarchical modelling structure of the library. Alongside, key modeling concepts are presented. Finally, the integrated analysis capabilities are highlighted and briefly demonstrated based on classic hybrid power train architecture.
\end{abstract}

Keywords: $\quad$ hybrid-electric power trains, electric flight

\section{Introduction}

In order to meet the challenging $\mathrm{CO} 2$ emission goals defined for aviation in Flightpath 2050 (compare European Commission, 2011), new disruptive aircraft developments are required to accelerate the progression of aviation technology. In addition to novel airframe and engine technologies, hybrid electric aircraft propulsions systems constitute a promising avenue for future developments by extending the design space for potential aircraft configurations (see Figure 1). This extension includes for instance electrical energy storages, or airframe integration concepts of the propulsion systems like boundary layer ingestion and distributed propulsion. Therefore similar to the automotive sector, a research trend for hybrid electric propulsion systems rose up in aviation over the last years (Hepperle, 2012). Besides the numerous studies published by NASA (SCEPTOR focusing on distributed propulsion, STARC-ABL focusing on boundary layer ingestion, SUGAR Volt), also leading companies in Europe collaborate in studies on hybrid electric aviation (compare Siemens Extra 330, Airbus E-Fan X).

In the context of hybrid electric propulsion systems in aviation, novel power train architecture topics emerge along with the classic aircraft design challenges. In turn, this enquires for a propulsion system analysis tool providing a proper framework for the analysis of the various power train architectures of interest and trade studies amongst them.

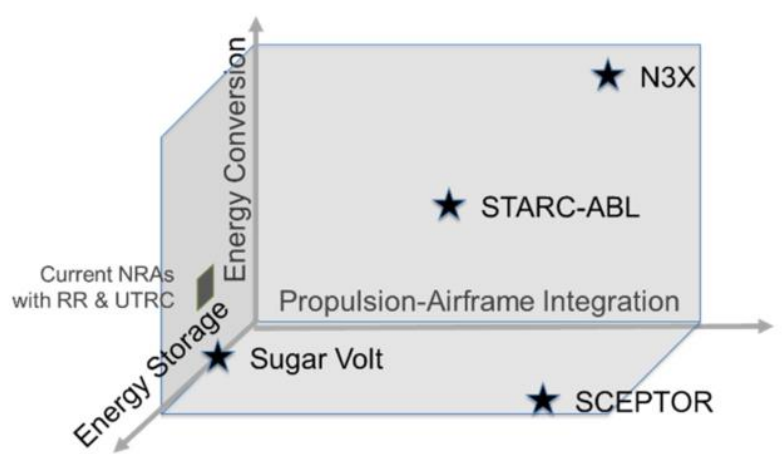

Figure 1. Additional dimensions of the design space availed by hybrid electric propulsion (Jansen, 2016).

\subsection{State of the art Modelica libraries}

The modeling of hybrid-electric powertrains is one of the first and most prominent applications of Modelica as the DLR Powertrain Library (Tobolár, 2007) for the automotive sector documents since over 10 years.

For aviation, similar approaches have been undertaken in the frame of individual projects. This includes the modeling of more-electric architectures for power and thermal management (Schlabe, 2012, 2015) as well the modeling of unmanned high-altitude platforms operating on solar energy (Klöckner, 2013).

Regarding electric propulsion of passenger aircraft, first studies with Modelica were performed by (Kastner, 2016) and dedicated frameworks are currently built up as in (Batteh, 2018). Meanwhile a number of research projects are dedicated to the topic of electric propulsion and the library of this paper shall be one of the needed building blocks for early design and optimization.

\subsection{Specification for a hybrid electric power train modeling environment}

The environment is meant to accompany the design process thought the different design stages ranging from basic concept studies to detailed architecture analysis. Thus, one of the main challenges is to pinpoint the required level of detail representing the significant effects for the phenomenon under investigation while neglecting insignificant second order effects with minor contributions to alleviate the computational effort. If the models are interchangeable, 
the modelling complexity becomes selectable for various investigation interests and can be set to aimed for fidelity level accordingly. To meet these requirements, the framework of library must be object oriented to allow for interchangeable models of various complexities and detailing.

In addition to the different levels of detail in the modeling of components and subsystems, the framework is required to accommodate a variety of potential power train architectures (compare Figure 2). Thus, the interface definition between the components and subsystems becomes a matter of interconnectability, and flexibility in the number of power train subsystems. To enable such flexibility, the modeling framework is obligated to confine the modeling complexity in the subsystems relaxing the computational effort for the simulation of the power train and the equation system for the initialization. This requirement calls again for an object oriented approach which also supplies the user with a building set for the diverse power train architectures.
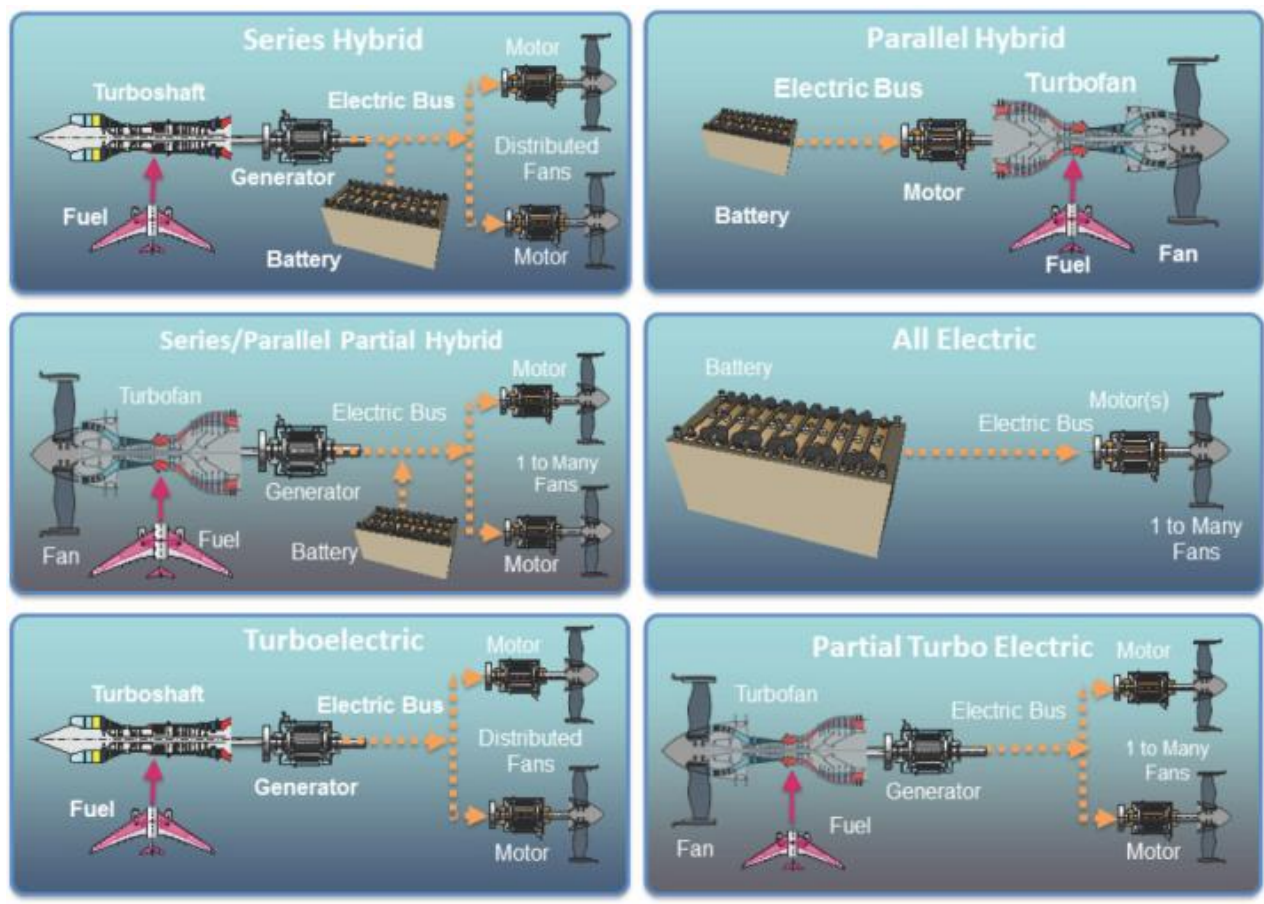

Figure 2. Categorization of the potential power train architectures for hybrid electric propulsion systems in aeronautics (National Academies of Sciences, Engineering, and Medicine, 2016).

In addition to the topology requirements, different operation strategies can lead to components changing their power flow direction during a flight simulation. E.g. an electric motor assisting the main engines during top of climb might be used as a generator to charge the battery pack during cruise. Hence, the non-causal approach from Modelica has an advantage over causal modeling tools like Simulink.

The modelling as well as the conception of hybrid electric aircraft is highly interdisciplinary due to the

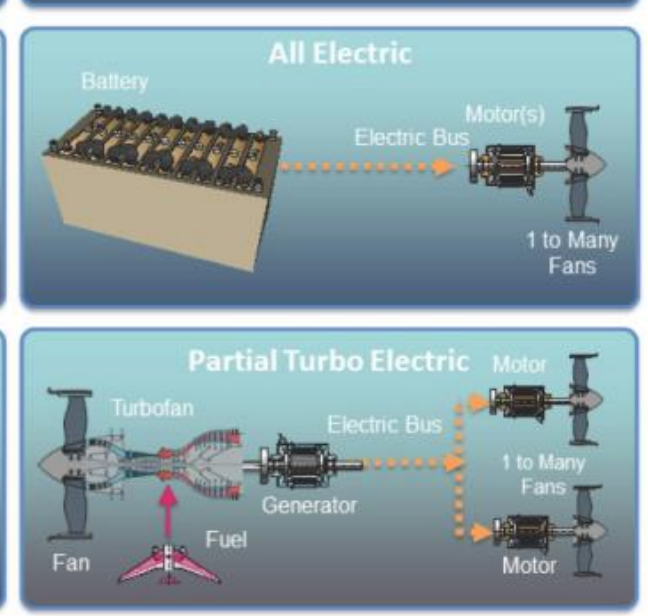

strong coupling of the subsystems in an aircraft. This apparent coupling inhibits limiting the benefit analysis to the isolated power train since efficiency gains on the power train level are not directly reflected onto the aircraft level. Other effects as additional drag (e.g. for changed/additional nacelles or cooling demand) and additional weight of the power train might cancel the drive train benefits partially or even surpass the benefit inducing an overall disadvantage on system level. Hence, the repercussion of the power train on the other subsystems of the overall aircraft has to be taken into account necessitating a holistic analysis of the hybrid electrically propelled aircraft. To accommodate the variety of domains and disciplines, Modelcia evidently is a proper modelling environment.

Besides the modeling of the components and subsystems, the coordination of the power flow between components embodies a main challenge for the environment framework. Furthermore for consistency purposes, physical system constraints must be taken into account and be avoided during system

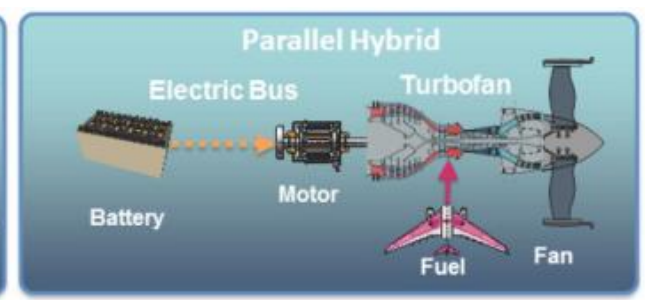


though it constitutes a major challenge in hybrid electric aircraft propulsion. However, the interfaces have already been adapted for future use. Besides the overall power train analysis, the library is intended to also provide means of testing and analysis tools for subsystems of the drive train which could be extended to unit testing for the process of sizing or modeling. During the implementation of the environment in Modelica, issues like the combined initialization of the power train and the aircraft, confining the model complexity in subsystems and defining a common framework for various power train topologies have to be addressed.

\section{Organization of the modeling of the hybrid electric power train}

In the following, the hierarchical organization of the power train models is presented and the concepts as well as the interfaces for linking the subsystems and portraying the framework for the model interaction are introduced.

\subsection{Hierarchical structure of the power train models}

The power train models are subdivided into three hierarchy layers: One layer for the overall power train level, one layer for the subsystems and one layer for the components of the respective subsystems of the propulsion units subsequently referred to as power train participants. For the combination of the overall power train model with a lumped aircraft model, an additional top level hierarchy is called for. The layer incorporating this level contains in addition to the hybrid electric power train a flight mission, a reference aircraft as well as the respective autopilot flying the desired mission (see Figure 3).

\subsection{The power train level model}

To handle the complexity and to ease the orientation of the user, the power train is subdivided into main power train participants (hybrid electric turbofans, electric fans, battery packs, turbofans, turbine propelled generators), a component representing the central DC backbone modeling the grid condition, an interface component for the aircraft power train interface, a central management unit for thrust and power distribution control, and collectors for the thrust and fuel flow (see Figure 4). Besides the physical interconnection of the power train participants via the DC backbone bus transferring the electric power between the components, a second bus is established. This central power train bus handles all power train internal communication and also forwards the aircraft information to the subsystems.

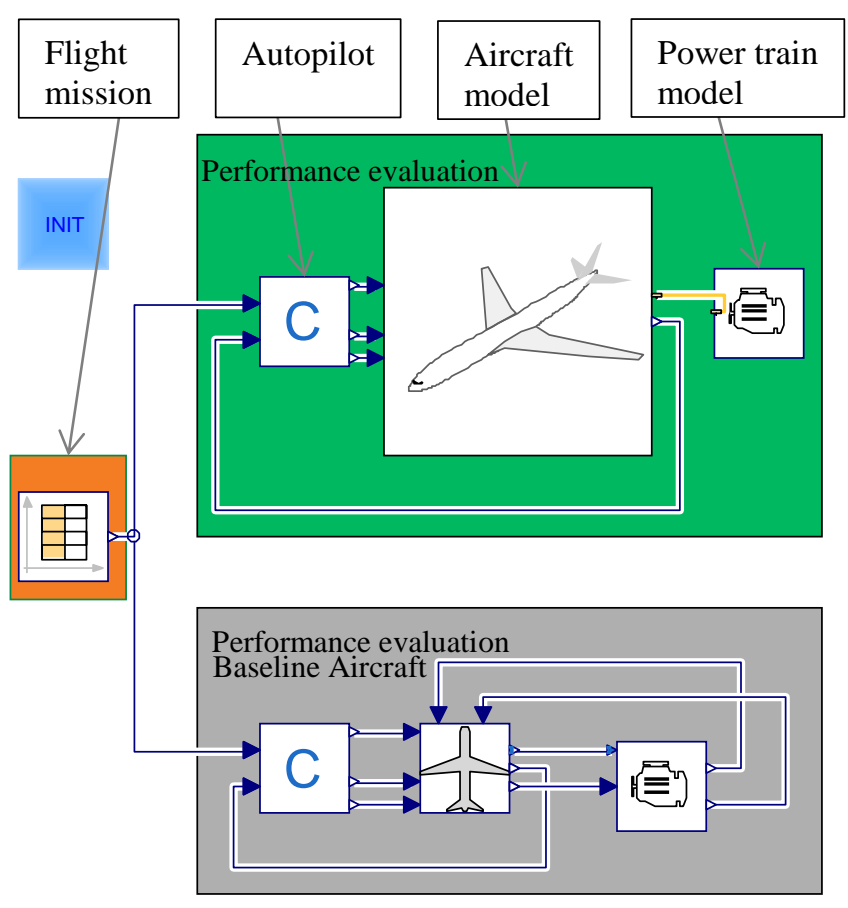

Figure 3. Top level layer for the combination of the power train library with an external lumped aircraft modelling library.

To guide the user through power train models, a graphical template depicting an aircraft sketch is used. The power train participants can be put to their respective position leading to a direct understanding of the basic power train architecture and the interaction between the subsystems. It also serves the system engineer as a standardized representation of the power train.

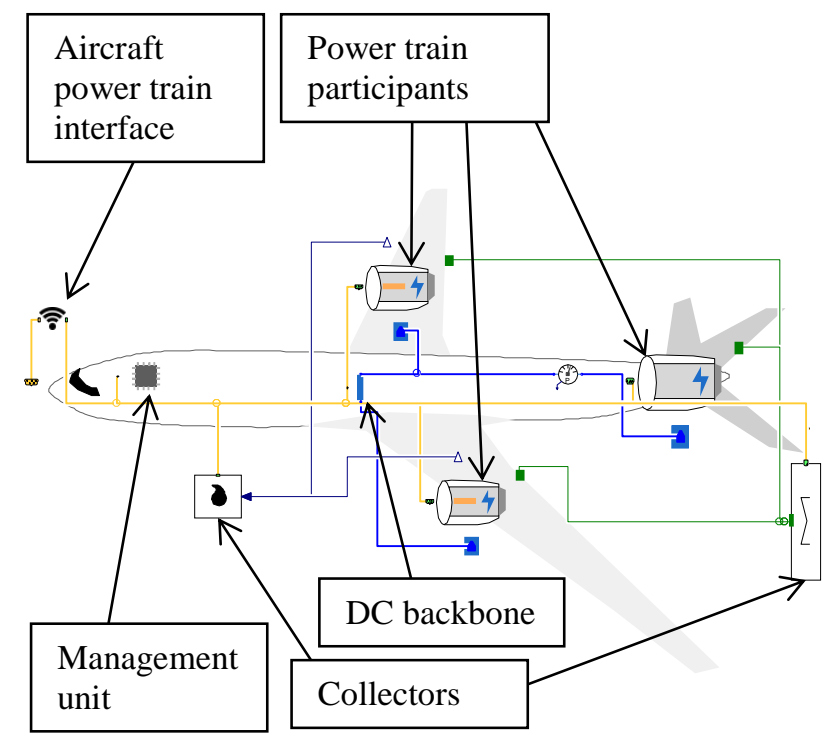

Figure 4. Power train architecture level for an exemplary partial turbo electric power train configuration. 


\subsection{Aircraft power train interface}

The purpose of this component is to define the interface between the aircraft model and the power train model. While the aircraft receives information on the thrust provided by the power train and its fuel consumption, the power train is supplied with atmosphere and flight state information like the velocity and the Mach number the aircraft operates at. The exchanged information is displayed in Table 1. Further to ease the compatibility between power train and aircraft model, the naming conventions of the respective libraries can be mapped in this component.

Table 1. Information flow in the aircraft bus

\begin{tabular}{|l|c|}
\hline $\begin{array}{l}\text { Information flow from } \\
\text { the aircraft to the } \\
\text { power train }\end{array}$ & $\begin{array}{l}\text { Information flow from the } \\
\text { power train to the } \\
\text { aircraft }\end{array}$ \\
\hline $\begin{array}{l}\text { Thrust scheduled by the } \\
\text { autopilot }\end{array}$ & $\begin{array}{c}\text { Thrust provided by the } \\
\text { power train }\end{array}$ \\
\hline $\begin{array}{l}\text { Aircraft state: Mach } \\
\text { number, true air speed }\end{array}$ & $\begin{array}{c}\text { Fuel flow leading to a } \\
\text { variation of the aircraft } \\
\text { weight }\end{array}$ \\
\hline $\begin{array}{l}\text { Atmosphere data: air } \\
\text { density, ambient tem- } \\
\text { perature (or condensed } \\
\text { in altitude information } \\
\text { based on the ISA } \\
\text { standard atmosphere) }\end{array}$ & $\begin{array}{c}\text { Excess thrust demand } \\
\text { surplus to the maximum } \\
\text { available thrust of the } \\
\text { power train (as feedback } \\
\text { information for the } \\
\text { autopilot) }\end{array}$ \\
\hline
\end{tabular}

Secondly, this interface component can be used to decouple the initialization of the power train and the aircraft model. A simultaneous steady-state initialization of both aircraft and power train model can be numerically challenging for various flight conditions due to the occurring non-linearities and constitutes one of the major challenges in modeling of hybrid electric powertrains.

In more concrete terms: for initializing the aircraft in a specific flight state within its envelope, only the altitude and path angles and the flight velocity/ the attitude are predefined. Hence, the thrust demand is an iteration variable of the aircraft initialization and not specified by the user. The power train is in turn to be initialized for a specific thrust demand and needs to handle numerous interpolations as well as nonlinear equations. Thus, the combined initialization of an aircraft in a quasi-steady state at an arbitrary start point results in a complex equation system which can be of poor condition. Hence, this added complexity resulting from the power train model could impede the overall initialization or possibly lead to degenerated solutions. To ease the initialization, the powertrain and aircraft model can be decoupled at initialization and a subsequent blending process makes the power train and the aircraft model converge to a meaningful common set-point.

\subsection{Central power train bus}

The central control bus is depicted by the yellow line in Figure 4. This bus broadcasts the atmosphere data as well as flight state data relevant for fans, engine cores and turbofans obtained at the aircraft power train interface, the control signals provided by the central management unit, measured signals required for the management of the power train and the information to be send back to be aircraft model (e.g. fuel mass flow, thrust provided by the power train).

To cope with a variable number of powertrain components, the control and measurement signals are implemented as arrays of variable size. To prevent overlapping of signals in these arrays, a numbering of the components is introduced serving as ID. Its consistency is currently to be granted by the modeler. In future, the UID library may be used instead (Hellerer, 2017). The power train components set and get the information in the respective array position defined by their numbering. The bus is expandable to allow the user to dynamically adapt it to the signals required in the topology or at the aimed for fidelity level, respectively.

\subsection{DC-Backbone}

The majority of the promising architectures for hybrid electric aircraft propulsion rely on a high voltage DCbackbone ( $\mathrm{kV}$ region) for the distribution of electric energy in the system. In the example of Figure 4 , the DC-Backbone is depicted as blue electric connection between the main components. As found in literature (Shuai et al, 2018; Chen, 2012), the basic dynamics of a DC backbone can be modeled by a capacitance relating the difference between feed currents and currents drawn from the grid to a change in the grid voltage. In a physical system, the grid capacitance represents the electric inertia of the cabling and also accumulates contributions from the input/output filter capacitances of the power converts connecting the power train participants to the DC backbone (if not modeled separately). Hence, the change in the grid voltage contains direct information on power distribution imbalances which consequently can be exploited for the management of the power train. To make this information available for the power management unit, it is broadcasted in the central power train bus.

The different actors on the backbone are similar to participants in a micro grid system. In a micro grid the behavior of the participants is organized in multiple levels (Shuai et al, 2018). This basic concept is adapted here. In our library two levels are defined: A primitive voltage-level based behavior serving as hard constraint and a top-level coordination logic trying to enforce the desired power flow by a certain management strategy on the components with subject to the lower level voltage based constrains. 
In the library, the primitive level does not solely monitor the grid voltage but also the power train participants. Considering that electric machines are relating the rotational speed of the shaft to a certain back EMF voltage, also limitation for the shaft speeds can be implemented on voltage level basis. Moreover, the battery pack voltage can serve as measure for the remaining capacitance and utilized for the consideration of the capacitance limit. Hence, the primitive level assures system protection and robustness in off-design regions potentially caused by improper sizing of the power train and failure cases.

The main power management is realized by a central control logic and sets the current flow between the different power train participants and the DC-backbone as well as the thrust split amount the propulsion units. The sources feeding current to the backbone try to stabilize the voltage while the loads try to achieve defined subsystem set points (e.g. fixing a fan shaft speed according to a desired thrust setting by feeding current into an electric machine) by drawing current from the backbone. Hence, the power exchange with the grid is realized on current level. The low level constraint enforcement is implemented locally in the respective power train components as dynamic saturation for these current signals and linearly down scales the maximum allowable current in vicinity of the voltage bounds.

At this stage, all sub-systems are connected to the DC-backbone via power converters acting according to the two coordination levels and serving as main drivers for the power distribution.

\subsection{Central power management model}

This component contains the system level logic (top level management) for operating the power train. The control signals calculated within this component are normalized such that all controller outputs range inbetween the interval of -1 to 1 for bi-directional components (that may act as both source and load) and 0 to $-1 / 1$ for unidirectional components (that may act exclusively as source or load). In the power train participants, this signal is scaled by the maximum power capability of the respective power converter or component. Hence, a value of -1 represents a maximum power to be drawn from the grid while a value of 1 represents a maximum power to be provided by the component. The main power flow direction for the electric systems is hence defined to be towards the grid. For instance, in case of the engine cores, the power flow is unidirectional and ranges from 0 to 1 . The normalization of the control signals simplifies the reusability of the respective central management units since proper scaling is not performed centrally in the management logic and becomes sizing independent. All control and measurement signals are broadcasted in the central power train bus (see section 2.4).
Because of the non-linearity in many power train participants, a direct stipulation of the set point by means of algebraic equations may lead to difficult to solve non-linear equation systems. Hence, the implementation of the central power management follows a rapid-prototyping control approach which converges the subsystems to defined set points. This approach allows for confining the nonlinearities in the components and enables the robust modeling and simulation of a variety of different architectures via control states. The goal is hence not to implement a realistic controller but rather the power management is seen as an enabler to simulate the complete system at the desired set-point. Because of the rapid-prototyping approach, simple PI controllers with anti-windup are used. The anti-windup is modified to also consider external saturations and limitations in form of the primitive level of the grid management (introduced in section 2.5).

Also on the level of the power train components, a local control logic may be additionally implemented. The nominal value for the local control variables is again managed centrally in the main management unit. Examples for such a local logic are all forms of turbofans. Since these can provide a set thrust autonomously (subjected to the engine core constraints), a local control is preferable.

However, the engine cores of hybrid electric turbofans can be assisted by an electric machine during critical operation conditions otherwise dominating the sizing. Moreover, they can provide power to the grid if excess power of the engine core is accessible. Hence a central control for the electrical support provides more flexibility.

\subsection{Power train component models and their interfaces}

The different power train components considered at this stage are (geared) turbofans, (geared) hybrid electric turbofans, electric fans and battery packs. These power train subsystems are the main building blocks for hybrid electric propulsion systems in aviation. Similar to the power train model, a template for organizing these subsystems is provided (as illustrated in Figure 5). The subsystems themselves are built with the aid of component modules allowing for a quick adaption of the fidelity level. 


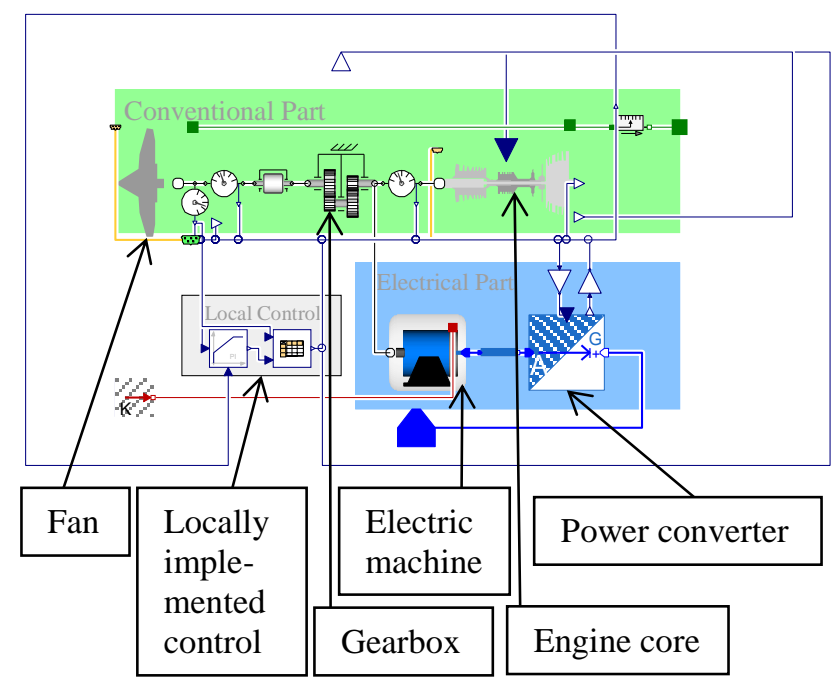

Figure 5. Power train architecture level for an exemplary partial turbo electric power train configuration.

For the junction between fans, engine cores and electric machines, the connector from the rotatory mechanics standard library is chosen since it provides a shaft speed and torque interface. This information is in turn required to calculate the efficiency and the back EMF of the electric machine. Furthermore, the interface is capable of portraying the shaft speed and torque characteristics of fans for different ambient conditions, flight speeds and thrust outputs.

For an electric fan and a hybrid electric turbofan, the sizing torque and the nominal speed of the electric machine are dependent of the operation strategy and the characteristics of the turbomachinery. Thus, this approach also allows for checking the sizing of the electric machine and for analysis of the operation points it is subjected to.

The electric interface is based on the DC interface provided by the standard library. AC subsystems are modeled via DC surrogate models in the dq0 frame.

\section{Analysis framework}

In correspondence to the hierarchy levels, three levels of analysis are designated in the current state of the library: A component level investigation frame to provide means of performing subsystem and component test in static steady state condition (static environment), a quasi-steady state frame in which the subsystems and components can be subjected to the demands and environment conditions of a classic flight mission (indirect aircraft environment), and a combined simulation of the lumped aircraft and the overall power train (aircraft environment). For the latter a second library contributing a lumped aircraft model, a flight mission, and an autopilot model is required. By default a library based on the Base of Aircraft Data 3.7 standard (BADA) (for details see (Eurocontrol Experimental Centre, 2009)) is availed as default. This library encompasses three degrees of freedom aircraft models, a standard mission and an autopilot. The BADA standard also contains information on the classic propulsion system for the included aircraft. Therefore, it can also serve as reference configuration for classical propulsion systems. As aforementioned, the combined simulation of the lumped aircraft and the power train is the level of analysis providing meaningful flight performance results for hybrid electric aircraft. The other two levels of analysis can be utilized as intermediate analysis for building up architectures from the scratch and to preliminary tune their parameters if no external sizing tool is accessible. Furthermore, these steps can be used as check for external sizing results. However, the quasi-steady state simulation can also be instrumented for simply assessing the influences on power train level. A summary of the capabilities for the 3 levels is given in Table 2.

Table 2. Capabilities of the different test levels.

\begin{tabular}{|l|c|c|c|}
\hline $\begin{array}{l}\text { Testing } \\
\text { Capabilities }\end{array}$ & $\begin{array}{l}\text { static } \\
\text { environ- } \\
\text { ment }\end{array}$ & $\begin{array}{l}\text { indirect } \\
\text { aircraft } \\
\text { environ- } \\
\text { ment }\end{array}$ & $\begin{array}{l}\text { aircraft } \\
\text { environ- } \\
\text { ment }\end{array}$ \\
\hline $\begin{array}{l}\text { For the thrust in } \\
\text { critical design } \\
\text { points on sub- } \\
\text { system level }\end{array}$ & $\mathbf{x}$ & - & - \\
\hline $\begin{array}{l}\text { For the thrust in } \\
\text { critical design } \\
\text { points on power } \\
\text { train level }\end{array}$ & $\mathbf{x}$ & - & - \\
\hline $\begin{array}{l}\text { for quasi-steady } \\
\text { state simulations }\end{array}$ & - & $\mathbf{x}$ & $\mathbf{x}$ \\
\hline $\begin{array}{l}\text { For hand tuning } \\
\text { the sizing of } \\
\text { components in a } \\
\text { subsystem }\end{array}$ & $\mathbf{x}$ & $\mathbf{x}$ & - \\
\hline $\begin{array}{l}\text { For analysis of } \\
\text { the power train } \\
\text { level benefit }\end{array}$ & - & $\mathbf{x}$ & $\mathbf{x}$ \\
\hline $\begin{array}{l}\text { For analysis of } \\
\text { the aircraft level } \\
\text { benefit }\end{array}$ & - & - & \\
\hline
\end{tabular}

\section{Exemplary a power train analysis}

\subsection{Description of the power train architecture}

For demonstration purposes, a parallel hybrid with two main hybrid electric turbofans (see Figure 6) is analyzed with the presented Modelica library. In the selected analysis scenario, the engine cores of the hybrid electric turbofans are undersized and are backed up by electric machines. The power for the electric 
machines is supplied to the DC-backbone by a battery pack. The power train is operated such that the electric motors buffer the power demand of the fans if the engine cores approach the vicinity of their power limit. To show the capability of a combined simulation of the aircraft and the power train, an aircraft environment type simulation is selected utilizing the default BADA library. As aircraft data set, A320 is picked. The mission profile is based on a typical medium distance mission for an A320.

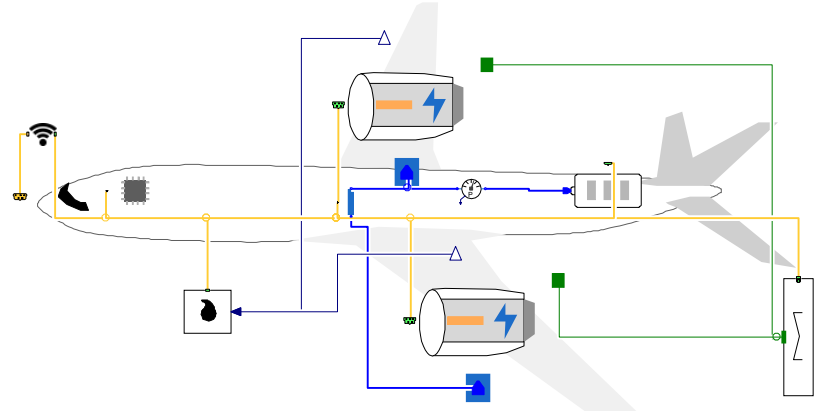

Figure 6. parallel hybrid with two main hybrid electric engines.

\subsection{Analysis revealing main features of the library}

As depicted in Figure 7, during takeoff and in the approach phase, the engine cores can provide all the power required to propel the fans. Close to the final cruise altitude (at ca. $5300 \mathrm{~s}$ ), the electric machines back up the engine cores to provide sufficient power for fans.

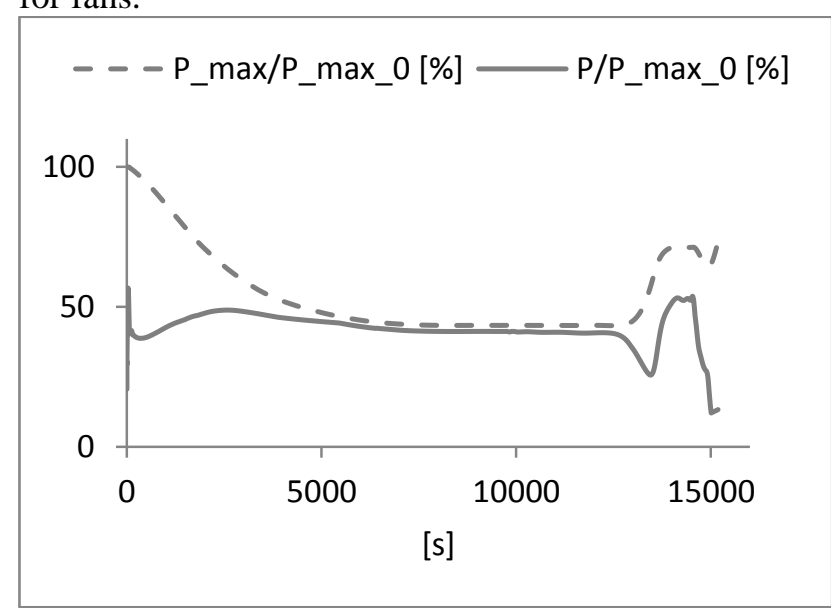

Figure 7. Power provided to one fan by the respective engine core (solid line) and maximum power of the respective engine core (dashed line) normalized by the maximum takeoff power [\%].

The power consumed by the electric motors is drawn from the grid by the respective power converters. Consequential, the power converter controlling the power flow of the battery pack tries to fix the voltage set point for the backbone by feeding power into the backbone. At ca. 6300s the power rating of the battery pack inhibits the controller dominating the battery pack behavior from stabilizing the backbone (as apparent in Figure 8). Hence, the backbone voltage drops (see Figure 9) until the vicinity of the lower operation bound of the backbone is reached. At this point the current rating for the motor control is down scaled by the primitive level to equilibrate the power rating of the battery pack and the motors. As soon as the power rating becomes adequate to balance the full load demand, normal grid operation is restored (as illustrated in Figure 9 at ca. 7200 s). In the meantime, the thrust demand of the autopilot cannot be achieved due to a lack in power rating. For normal mission operation, this issue does not arise for a properly sized power train because the sizing is also considering component faults.

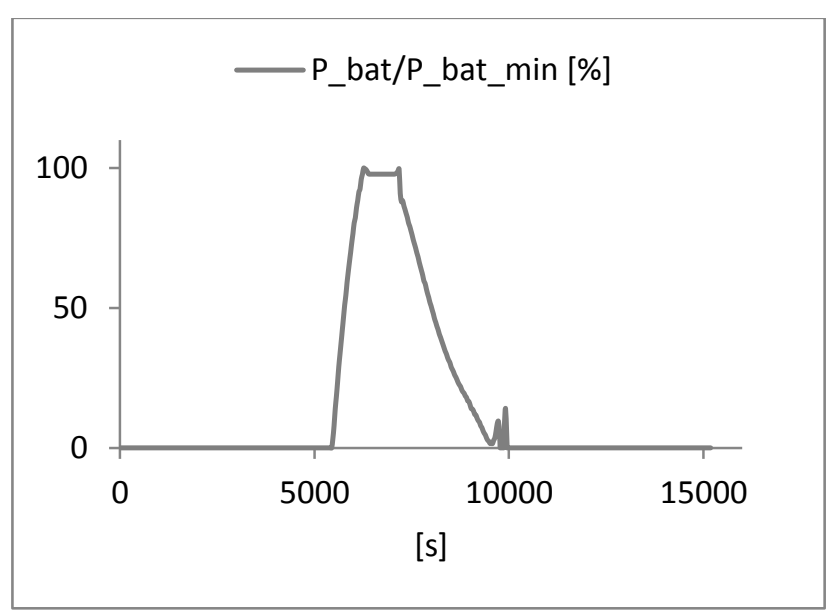

Figure 8. Power supplied to the DC-backbone by the battery pack normalized by the maximum output power [\%].

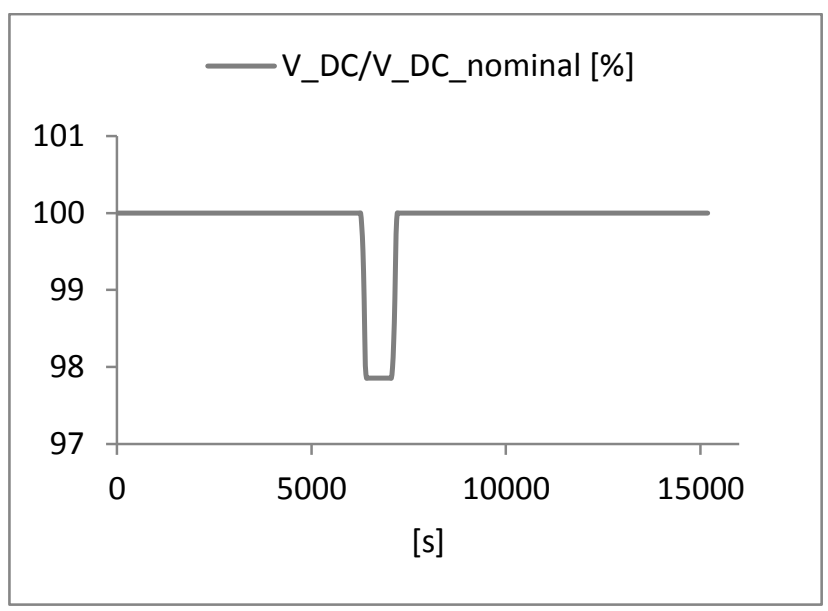

Figure 9. DC-backbone voltage normalized by the nominal voltage [\%].

The drop in its energy content of the battery caused by the power feed to the grid is depicted in Figure 10 . It can be seen that a surplus of energy remains for the selected mission. 


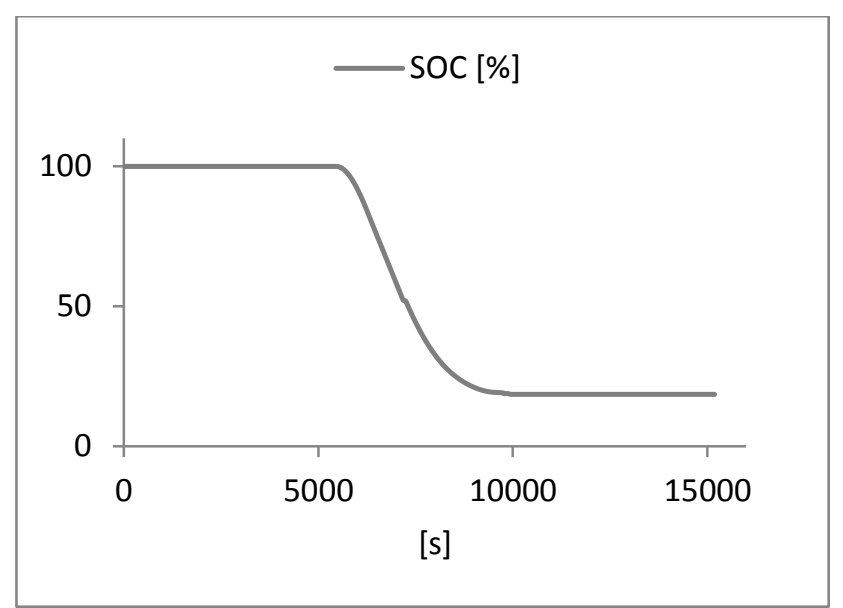

Figure 10. state of charge of the battery pack[\%].

\section{Conclusion and future work}

The current library can handle varying numbers of power train participants and gives insight into the first order interactions between the power train participants. It can serve as analysis tool for pre-sized power trains. Furthermore, the capability of a combined simulation of an aircraft model and the power train over a whole flight mission has been proven.

Currently, the thrust collector does not consider the position of the different propulsion units. For extending the library for simulation of system failures also the torques created by off centered thrust must be expressed by the power train model. Furthermore, a coupling the library with a six degree of freedom capable aircraft modeling environment like DLR Flight Dynamics library (Klöckner 2014) will be undertaken.

The main missing part of the analysis is the modeling and sizing of the cooling system for the electric components since its additional weight and power demand in form of electricity and drag has a significant effect on aircraft level. 


\section{References}

Eurocontrol Experimental Centre. User Manual for the Base of Aircraft Data (BADA) Revision 3.7, 2009.

European Commission. Flightpath 2050: Europe's Vision for Aviation, 2011.

Ralph H. Jansen, Cheryl Bowman and Amy Jankovsky. Sizing Power Components of an Electrically Driven TailCone Thruster and a Range Extender. 16th AIAA Aviation Technology, Integration, and Operations Conference, 2016, doi: 10.2514/6.2016-3766.

Loan T. F. W. Silva, Lucas P. Resende and Marcelo A. Tomim. Mathematical modeling and numerical simulation of locomotives electrical drive systems in Modelica, Brazilian Power Electronic Conference (COBEP), pp. 1-8, 2017.

Zhikang Shuai, Junbin Fang, Fenggen Ning, Z. John Shen. Hierarchical structure and bus voltage control of DC microgrid. Renewable and Sustainable Energy Reviews, Volume 82, Part 3, pp. 3670-3682, 2018.

Dong Chen and Lie Xu. Autonomous DC Voltage Control of a DC Microgrid With Multiple Slack Terminals. IEEE Transactions on Power Systems, vol. 27, no. 4, pp. 1897 1905, 2012.

National Academies of Sciences, Engineering, and Medicine. Commercial Aircraft Propulsion and Energy Systems Research: Reducing Global Carbon Emissions. The National Academies Press, 2016, doi: 10.17226/23490.

Martin Hepperle. Electric Flight - Potential and Limitations. NATO Science and Technology Organization, 2012, ULR: https://elib.dlr.de/78726/, [retrieved 2018].

Matthias Hellerer and Fabian Buse (2017) Compile-time dynamic and recursive data structures in Modelica. In: Proceedings of the 8th International Workshop on EquationBased Object-Oriented Modeling Languages and Tools (EOOLT), Munich, Germany.

Klöckner, Andreas, Looye, Gertjan et. al. (2014) ObjectOriented Aircraft Modeling with the DLR FlightDynamics Library. 9th AIRTEC 2014 International Congress, 28 - 30 Oct. 2014, Frankfurt, Germany.

Jakub Tobolář, Martin Otter and Tillman Bünte: Modelling of Vehicle Powertrains with the Modelica In: Systemanalyse in der Fahrzeugtechnik IV

Klöckner, Andreas und Leitner, Martin und Schlabe, Daniel und Looye, Gertjan (2013) Integrated Modelling of an Unmanned High-Altitude Solar-Powered Aircraft for Control Law Design Analysis. In: Advances in Aerospace Guidance, Navigation and Control. EuroGNC 2013, 2nd CEAS Specialist Conference on Guidance, Navigation \& Control, April 10-12, 2013, Delft, The Netherlands.

Schlabe, Daniel (2015) Modellbasierte Entwicklung von Energiemanagement-Methoden für FlugzeugEnergiesysteme. Dissertation, Technische Universität Dresden.

Schlabe, Daniel und Zimmer, Dirk (2012) Model-Based Energy Management Functions for Aircraft Electrical Systems. SAE Power Systems Conference 2012, 30. Okt. 01. Nov. 2012, Phoenix, USA.

Kastner, Nir (2016). Modelica environment of hybridelectric propulsion. Presentaiton on electric \& hybrid technology symposium. Cologne, Germany.
John Batteh et. al. (2018) Development and Implementation of a Flexible Model Architecture for Hybrid-Electric Aircraft In: the American Modelica Conference 2018. 
